\title{
Imagens, livros didáticos e colonialidade
}

\author{
Imágenes, libros escolares y colonialidad \\ Images, textbooks and coloniality
}

\section{Daniel Guillermo Gordillo Sánchez ${ }^{1}$}

\begin{abstract}
Resumo
O pensamento moderno europeu, sustentado no projeto intelectual do Iluminismo, acabou por instaurar as suas epistemologias nas colônias. Nesse processo, ainda vigente, fabricou-se uma concepção de conhecimento que se reclamava a si mesmo o direito de ser universal, válido e demonstrado. De tal forma, a subalternização e violência física dos impérios contra os povos originários, devia, inexoravelmente, apoiar-se em processos de violência epistémica, de "epistemicídios", ou na imposição de certas racionalidades em detrimento das formas locais de produção de conhecimento. Assim, este trabalho parte da premissa que a violência também se mostra como um espaço de poder onde se reproduzem representações hegemónicas sobre o Outro indígena, desvalorizado, estereotipado e invisibilizado sistematicamente conforme os interesses das elites econômicopolíticas. Da mesma forma, acreditamos que os legados epistêmicos da colonialidade são palpáveis na escola e, principalmente, nos livros didáticos, espaços etnográficos férteis para problematizar os efeitos do projeto colonizador e capitalista de ocidente. Destacamos a utilidade teórico-metodológica destes documentos para analisar a conformação de imaginários sobre os índios e a produção de uma versão da história que busca sedimentar uma identidade nacional determinada. Apresentaremos os resultados preliminares de uma pesquisa de mestrado, concentrada nas formas como é representado o indígena nos livros didáticos de História das escolas municipais da cidade de Foz do Iguaçu. A partir da seleção de algumas imagens obtidas nos livros buscamos problematizar estereótipos e equívocos sobre a questão indígena, e sua relação com os processos de violência contemporânea que sofre o povo indígena Guarani.
\end{abstract}

Palavras-Chave: colonialidade, ensino de história, indígenas Guarani, livros didáticos, violência epistêmica.

\section{Resumen}

El pensamiento moderno europeo, sustentado en el proyecto intelectual de la Ilustración, acabó por instaurar sus epistemologías en las colonias. En ese proceso, aún vigente, se fabricó una concepción de conocimiento que se reclamaba a sí mismo el derecho de ser universal, válido y demostrado. De tal forma, la subalternización y la violencia física de los imperios contra los pueblos originarios, debía, inexorablemente, apoyarse en procesos de violencia epistémica, de "epistemicidios", o en la imposición de ciertas racionalidades en detrimento de las formas locales de producción de conocimiento. Así, este trabajo parte de la premisa de que la violencia también se muestra como un espacio de poder donde se reproducen representaciones hegemónicas sobre el Otro indígena, desvalorizado, estereotipado e invisibilizado sistemáticamente conforme los intereses de las élites económico-políticas. De la misma forma, creemos que los legados epistémicos de la colonialidad son palpables en la escuela y, principalmente, en los libros didácticos, espacios etnográficos fértiles para problematizar los efectos del proyecto colonizador y capitalista de occidente. Destacamos la utilidad teórico-metodológica de estos documentos para analizar la conformación de imaginarios sobre los indígenas y la producción de una determinada versión de la identidad nacional. Presentamos los análisis preliminares de una investigación de maestría, concentrada en las formas como es representado el indígena en los libros didácticos de historia de las escuelas municipales de Foz do Iguaçu. A partir de la selección de algunas imágenes obtenidas en los libros,

\footnotetext{
1 (Mestrando em Antropologia Social; Universidade Federal de Santa Catarina; Florianópolis, Santa Catarina, Brasil; Bolsista do Conselho Nacional de Desenvolvimento Científico e Tecnológico - CNPq; danielgordillo65@gmail.com.). Trabalho apresentado no I Seminário Latino-Americano de Estudos em Cultura - SEMLACult, Foz do Iguaçu/PR, Brasil, 2017.
} 
buscamos problematizar estereotipos y equívocos sobre la cuestión indígena, y su relación con los procesos de violencia contemporánea que sufre el pueblo indígena Guarani.

Palabras Clave: colonialidad, enseñanza de historia, indígenas Guarani, libros didácticos, violencia epistémica.

\begin{abstract}
Modern European thought, based on the intellectual project of the Enlightenment, ended up instituting its epistemologies in the colonies. In this process, still in force, a conception of knowledge was fabricated, claiming to itself the right to be universal, valid and proved. In such a way, the subalternization and physical violence of the empires against the native peoples must inexorably rely on processes of epistemic violence, of "epistemicides", or on the imposition of certain rationalities to the detriment of local forms of production of knowledge. So this work is based on the premise that violence is also shown as a power space where hegemonic representations of the Other indigenous, devalued, stereotyped and systematically invisible according to the interests of the economic and political elites are reproduced. In the same way, we believe that the epistemic legacies of coloniality are palpable in school and, especially, in schoolbooks, fertile ethnographic spaces to problematize the effects of the colonizing and capitalist project of the West. We emphasize that the theoreticalmethodological usefulness of these documents in order to analyze the conformation of imaginaries on the indigenous and the production of a certain version of the national identity. We present the preliminary analyzes of a master's research, focused on the forms represented by the indigenous in the textbooks of the municipal schools of Foz do Iguaçu. From the selection of some images obtained in the books, we look for problematize stereotypes and misunderstandings about the indigenous question, and their relation with the processes of contemporary violence suffered by the indigenous Guarani people
\end{abstract}

Keywords: coloniality, history education, Guarani indigenous people, textbooks, epistemic violence.

\title{
1. A cara epistêmica da colonialidade
}

A empresa colonial do século XV muito mais do que um empreendimento econômicopolítico, deve ser pensada como um projeto científico que estabeleceu um marco histórico que se adjudicou o direito de designar, classificar ou hierarquizar saberes, práticas e protocolos de conhecimento, descartando aqueles que não se enquadravam no modelo epistémico europeu. Isto foi fundamental para garantir o sucesso do projeto "civilizatório" moderno, sendo consubstancial ao extermínio físico que sofrem as populações indígenas em América Latina desde então. Pratt (1999, p.74) sugere que os pensadores do "Século das Luzes", porta-vozes da chamada "racionalidade", omitiram o papel dos agressivos empreendimentos coloniais e comerciais europeus, e seus efeitos genocidas na América Latina e na África. Segundo a autora de Olhos do Império, a Europa encarregou-se de elaborar um projeto classificatório mundial de aspirações continentais e transnacionais, para legitimar a escravidão de outros povos.

É fundamental frisar que esses processos de escravidão e opressão foram mantidos pelas elites criollas ou locais, descendentes de portugueses e espanhóis nascidos na América, que forjaram a independência. Dita situação se configura no que González Casanova (2009) definiu como colonialismo interno, um fenômeno que não é somente internacional senão intranacional também. Analisando o quadro social dos povos originários no México frente aos 
processos desenvolvimentistas desse país, o autor sublinha: "Pasamos del domínio de los nativos por los extranjeros, al domínio y la explotacion de los nativos por los nativos. La explotación de los indígenas tiene las mismas características que en la época anterior a la Independencia (GONZALEZ, 2009, p.131; grifo meu).

No livro A questão de América a questão do Outro, Todorov (2010) desvenda o grande 'choque cultural' entre dois mundos distantes, mostrando os mecanismos ativados na descoberta da diferença. $\mathrm{O}$ autor ressalta, entre outras coisas, a importância do ato de nomear, chave dentro da hermenêutica europeia sobre as Américas. Essa foi uma estratégia recorrente e de amplo alcance, usada por todos os impérios, para reforçar o processo de conquista e consagrar os novos territórios e as humanidades colonizadas. Todorov mostra como o conquistador se apaixona pela escolha dos nomes do mundo "virgem" que está conhecendo. Além disso, as denominações para ilhas, rios, montanhas, etc., guardavam um sentido religioso com Deus, a Virgem Maria, o Rei da Espanha e a Rainha, respectivamente (TODOROV, 2010, p.37).

Colombo sabe perfeitamente que as ilhas já têm nome (...) as palavras dos outros, entretanto, não lhe interessam muito, e ele quer rebatizar os lugares em função do lugar que ocupam em sua descoberta, dar-lhes nomes justos; a nomeação, além disso, equivale a tomar posse. (...) As coisas devem ter os nomes que lhes convêm. (...) Para ele a diversidade linguística não existe, o que é surpreendente na medida em que o próprio Colombo é poliglota" (TODOROV, 2010, p.38-41; grifo meu)

Se bem sabemos que o sucesso material e econômico dos europeus dependia, inexoravelmente, da expansão espiritual cristã, nesse processo também foi decisivo o ato de nomear, designar, classificar e intitular o mundo, ferramentas e recursos discursivos e ontológicos do Estado moderno. Isto foi, paralelamente, um ato de censura, indiferença e violência epistêmica sobre as tradições indígenas de conhecimento. Dessa maneira, pode-se afirmar que as atividades de classificar e representar estão extremamente relacionadas ao poder e à hegemonia. É através das representações que os indivíduos marcam de modo visível e perpetuo a existência do grupo, da comunidade ou da classe (CHARTIER, 1991, p.183).

Assim, consideramos chave retomar o problema da colonização na América Latina, sobretudo no relacionado aos mecanismos usados para representar, descobrir e construir o Outro (TODOROV, 2010; CASTRO-GOMEZ, 2005). Ao falar de invenção não nos referimos somente ao modo como um grupo representa mentalmente o outro, mas nos referimos aos dispositivos de saber/poder que servem de ponto de partida para a construção dessas representações. (CASTRO-GOMEZ, 2005, p.81).

À luz destas ideias, é possível acunhar o conceito de colonialidade, que se refere a "un patrón de poder que opera a través de la naturalización de jerarquías territoriales, raciales, 
culturales y epistémicas, posibilitando la re-producción de relaciones de dominación" (RESTREPO; ROJAS, 2010, p.15; grifo meu). A colonialidade se pensa, então, como a herança de uma rede de relações étnicas, raciais, sexuais, epistémicas e de género, que permanece enraizada nas sociedades colonizadas, e que deve ser desconstruída para repensar a nossa identidade desde a especificidade histórico-política das nossas sociedades (CASTROGÓMEZ; GROSFOGUEL, 2007; RESTREPO; ROJAS, 2010).

A colonialidade pode ser percebida desde uma perspectiva analítica de longa duração, para avaliar os efeitos do projeto moderno colonial no que se refere à violação de direitos contra os povos indígenas no nosso continente, compreendendo, é claro, que os episódios de violência física mantém uma relação simbiótica com processos de violência epistêmica (SPIVAK, 1988). De tal forma, é imperativo questionar o modelo de conhecimento instaurado pela modernidade, definida por Castro-Gómez (2005, p.81) como "uma máquina geradora de alteridades que, em nome da razão e do humanismo, exclui de seu imaginário a hibridez, a multiplicidade, a ambigüidade e a contingência das formas de vida concretas".

Espinoza (2007) argumenta que dentro dos estudos sociais sobre a violência não tem se aprofundado o suficiente ao redor das dimensões simbólicas que levam à desumanização das comunidades indígenas. Para esta pesquisadora a violência debe ser entendida como "ese espacio de poder en donde se encuentran y oponen representaciones hegemónicas del Indio como Otro, y formas de violencia arbitraria y reinscripciones insurgentes". (ESPINOZA, 2007, p.269). Logo, é uma tarefa dos pesquisadores examinar os distintos positivos veiculados pelas classes dominantes para desumanizar o outro diferente.

Levando em consideração esse marco introdutório, neste trabalho, interessa-nos desvendar o vínculo entre colonialidade, modernidade e violência epistêmica, a partir de uma análise sobre como é representado o indígena nos livros didáticos, no intuito de explorar os procedimentos utilizados pelas elites criollas para definir ao indígena como antagônico do processo civilizador moderno, inimigo do Estado-nação (ESPINOZA, 2007, p.272).

Apresentaremos algumas análises preliminares de uma pesquisa de mestrado em Antropologia Social da Universidade Federal de Santa Catarina - UFSC, concentrada nas formas como é representado o indígena nos livros didáticos de História usados nos anos iniciais do Ensino Fundamental nas escolas municipais de Foz do Iguaçu (PR). A partir das imagens obtidas nos livros de maior circulação, elaboraremos uma análise sobre o modo como aparece o sujeito indígena, seus costumes, características socioculturais e demandas atuais. Nesse sentido, oferecemos um marco interpretativo que nos permita elaborar outras 
leituras sobre a violência que atualmente sofre o povo indígena Guarani, sobretudo no relativo à problemática fundiária (BRIGHENTI, 2010).

\section{Os livros didáticos e a escola}

A escola tradicionalmente privilegiou a homogeneização e as desigualdades do sistema capitalista (SILVA, 2013:101), sendo um local onde se exerceu, sistematicamente um tipo de dominação epistêmica, de corte ocidental e moderno, negando e subalternizando os saberes e as identidades dos povos originários. Clovis Brighenti (2016, p.2016), em seu artigo A colonialidade e decolonialidade no ensino da história e cultura indígena, afirma que da escola é um dos suportes da colonialidade do poder, principalmente porque opera de maneira estratégica através da dominação epistêmica. Segundo o historiador, "alguns cenários evidenciam que muitas instituições de ensino, ao invés de agregarem os conhecimentos da história e a cultura indígena, reproduzem as tensões resultados do conflito latente em seu entorno" (BRIGHENTI, 2016, p.235).

Um fato histórico que busca mudar a concepção reducionista ou vaga sobre o índio no sistema escolar é a lei 11.645. Sancionada no ano 2008, torna obrigatório o ensino da história e a cultura afro-brasileira e indígena nos estabelecimentos de ensino fundamental e de ensino médio, públicos e privados no Brasil. Ela altera a Lei 9.394 de 1996 ou LDB (que estabelece as diretrizes e as bases da educação nacional), modificada pela Lei 10.639 de 2003 (que teve por propósito incluir nos currículos escolares a temática História e Cultura Afro-Brasileira). Assim, a lei 11.645 estipula que o conteúdo programático na rede de ensino

\footnotetext{
incluirá diversos aspectos da história e da cultura que caracterizam a formação da população brasileira, a partir desses dois grupos étnicos, tais como o estudo da história da África e dos africanos, a luta dos negros e dos povos indígenas no Brasil, a cultura negra e indígena brasileira e o negro e o índio na formação da sociedade nacional, resgatando as suas contribuições nas áreas social, econômica e política, pertinentes à história do Brasil. (Brasil, 2008).
}

A promulgação desta normativa é produto de inúmeros avanços e esforços. É importante sublinhar que é, acima de tudo, resultado de uma luta incansável dos movimentos sociais indígenas e negros, significando uma conquista histórica que atende às reivindicações destes grupos historicamente marginalizados e invisibilizados (SILVA, 2013), que pretende abrir um novo capítulo da educação brasileira. Com esta lei busca-se posicionar a escola como uma instituição comprometida com a formação de valores humanísticos, éticos, sociais e políticos, e, sobretudo, como um local de grande relevância para a inclusão do debate sobre a 
diversidade étnico-racial, procurando mitigar os preconceitos e as práticas discriminatórias (SILVA; SILVA, 2013, p.82).

Neste leque de possibilidades de transformação da instituição escolar, os livros didáticos, vistos como o subsidio mais usado para tratar os conteúdos pedagógicos na escola, podem ter um rol transformador. Certamente, o livro didático é um dos instrumentos mais usados no processo de ensino e aprendizagem dentro da escola, e, também, é o primeiro (muitas vezes o único) texto que as crianças leem em sua infância. Além disso, através dos conteúdos que mobiliza, o livro didático produz identidades e ideologias (CHARTIER, 1990; ATIENZA; VAN DIJK, 2010; OLIVEIRA, 2003).

Choppin (2004, p.553) sugere que o livro didático é uma construção simbólica ao nível da moeda ou da bandeira, e, nessa medida, concordamos com Bourdieu (1989, p.125) quando coloca que quem assume o papel de representar e classificar, é depositário de vantagens simbólicas associadas à posse de uma identidade legítima, suscetível de ser reconhecida como identidade nacional. De tal forma, é possível compreender que os livros e textos escolares não existem por si sós, senão que são produto de inúmeras e históricas relações de poder. Os livros didáticos tendem a apresentar o indígena como um personagem histórico e desaparecido (SANTOS, 1973, p.16). John Monteiro (1999, p.237) frisa que os manuais escolares tendem a liquidar as populações indígenas, dando-lhes certo destaque apenas nos anos iniciais da colonização.

Assim, observamos que os povos indígenas são citados nos livros didáticos quando se discute as origens da humanidade, na condição de "povos primitivos" (SILVA, 2014, p.33). Portanto, acreditamos que os livros didáticos e manuais escolares têm tido, historicamente, uma incidência direta na criação da ideia do Brasil "misturado", sem índios - ou com índios "aculturados" ou "civilizados", na melhor das hipóteses - seja pelas classificações que geram ou pela ausência delas, pelos chamados esquecimentos ou silenciamentos. Nesse quadro, os livros didáticos têm uma implicância séria na omissão da agência e da força de ação indígena, sendo esta restringida à dimensão da vítima ou do sujeito remanescente, quando está contemplada.

Algumas aproximações à literatura científica sobre as representações sobre os indígenas nos livros didáticos demonstram que neles costumam circular imagens, discursos generalizadores que marcam, estereotipam e excluem aos índios, veiculando lacunas, desinformação e desvios ideológicos presentes relativos à questão indígena (GRUPIONI, 1996; OLIVEIRA, 2003; AMAN, 2010; YAÑEZ, 2010; GOBBI, 2012). Nesta perspectiva, os livros e manuais escolares tendem a consagrar categorizações dos não indígenas, perpetuando 
relações de desigualdade e de colonialidade. De alguma maneira, ostentam um conhecimento vendido como neutro, válido e verdadeiro, responsável pelo processo que derivou na proibição explicita das epistemologias e ontologias dos povos originários. Sublinhamos que esta naturalização e condição de autoridade que guarda o livro didático dentro do sistema escolar faz com que não podamos visualizar a complexidade inerente que representa seu desenvolvimento histórico como dispositivo pedagógico e fonte legítima para problematizar as relações étnico-raciais na educação.

Sendo assim, o nosso desafio etnográfico consistiu em examinar quais são representações que se fazem sobre os indígenas nos livros didáticos utilizados nas escolas municipais, de 1ero a 5to ano, em Foz do Iguaçu, considerando as possiblidades, desafios e responsabilidades que supõe a promulgação da lei 11.645 de 2008. Com isto, este trabalho espera aportar elementos que problematizem sobre o presente e a contemporaneidade dos povos indígenas Guarani no oeste paranaense.

\section{Imagens como narrativa social}

Uma das características mais notórias dos livros didáticos e manuais escolares utilizados no ensino fundamental é o fato de serem bastante imagéticos e iconográficos. Estes textos constituem uma modalidade particular de material didático elaborado para fins pedagógicos, e, nessa medida, as imagens, figuras e ícones são recursos idôneos para organizar e difundir os conteúdos curriculares, principalmente nos primeiros anos da vida escolar. Sem dúvida, as imagens possuem um fator motivacional e comunicacional que convida à leitura, e, paulatinamente, introduzem às crianças ao mundo do conhecimento e a ciência. Nesse sentido, os livros didáticos da atualidade caracterizam-se por serem produções estéticas e gráficas muito bem elaboradas, denotando a preocupação editorial por incluir imagens de boa qualidade nos textos.

Entretanto, é importante ressaltar que, de alguma maneira, as imagens e representações visuais apresentadas nos livros didáticos tem "vida própria" e estão inseridas nas obras conforme uma intencionalidade, voltada a difundir e visibilizar certos princípios ou ideais. As imagens são o melhor guia para entender o poder, sendo documentos históricos, testemunhas oculares de uma época e dos eventos mais significativos de uma sociedade (BURKE, 2001). Isso nos permite afirmar que as imagens dos livros didáticos são produto de um devir histórico, que enaltecem sentidos - e omitem outros -, revelando as distintas relações de poder e os interesses simbólicos que prevalecem em um grupo humano. Sendo assim, as imagens, 
assim como seus textos acompanhantes, nos permitem examinar os componentes simbólicos imbricados nos processos de ensino-aprendizagem da escola, sendo fundamentais para compreender as sociedades modernas.

Para a análise das imagens recolhidas no nosso trabalho de campo (cujas condições e metodologias não poderemos desenvolver amplamente nesse texto) nos fundamentamos teoricamente na proposta de Silvia Rivera Cusicanqui (2010), que estuda as imagens como narrativas apreensíveis de análise histórica e sociológica. Para a socióloga indígena boliviana, as imagens permitem desmascarar as distintas formas de colonialismo contemporâneo (CUCICANQUI, 2010, p.9). Ela sustenta que as imagens oferecem interpretações sobre a vida social e permitem uma compreensão crítica da realidade. A autora ainda coloca:

\begin{abstract}
$\mathrm{Y}$ es en este marco que voy a hablar ahora sobre lo que llamo la sociología de la imagen, la forma como las culturas visuales, en tanto pueden aportar a la comprensión de lo social, se han desarrollado con una trayectoria propia, que a la vez revela y reactualiza muchos aspectos no conscientes del mundo social. (CUCICANQUI, 2010, p.19)
\end{abstract}

O corpo do nosso estudo está composto de cinco (5) livros didáticos de história, de distintas editoriais. Duas (2) obras que integram história para 4to e 5to ano, uma (1) obra de história para 5to ano, uma (1) obra de história para 4to ano (estes 4 livros, aprovados na última chamada do Programa Nacional do Livro Didático PNLD) e uma (1) coletânea elaborada no munícipio de Foz do Iguaçu. Para efeitos desta reflexão decidimos selecionar algumas imagens organizadas em quatro categorias de análise, que refletem e convergem situações, representações e perspectivas em comum. Estas categorias são: a) eurocentrismo e história, b) vazio demográfico e expropriação territorial, c) o fator turístico e discursos desenvolvimentistas, d) tradições e resistências.

Devido a este trabalho ser o fragmento preliminar de uma análise em curso (e de uma dissertação em construção), faremos uma breve descrição sobre as categorias a seguir. Por questões referentes ao espaço disponível neste artigo, esta discussão não poderá ser aprofundada com o rigor analítico que demanda. Contudo, a nossa reflexão se desenvolve à luz de algumas referencias bibliográficas centrais no nosso trabalho.

a) Eurocentrismo e história: Um dos aspectos mais recorrentes quando se examina a maneira e a linguagem como se descrevem e formulam os conteúdos históricos nos manuais escolares está relacionado com seu viés eurocêntrico. Privilegia-se a perspectiva dos espanhóis e portugueses quando se aborda conquista dos territórios e o sistema colonial, qualificando os indígenas como meras vítimas desse processo, mencionados somente quanto se trata de sua escravidão e exploração. O nativo aparece em um segundo plano nas relações coloniais, 
condenado a uma posição servil e expectadora. Reforça-se, desta forma, o eufemismo de "encontro de culturas" que mostra esse processo como dado de forma pacífica ou harmoniosa, omitindo o genocídio praticado pelos espanhóis e portugueses (Fotografia 1).

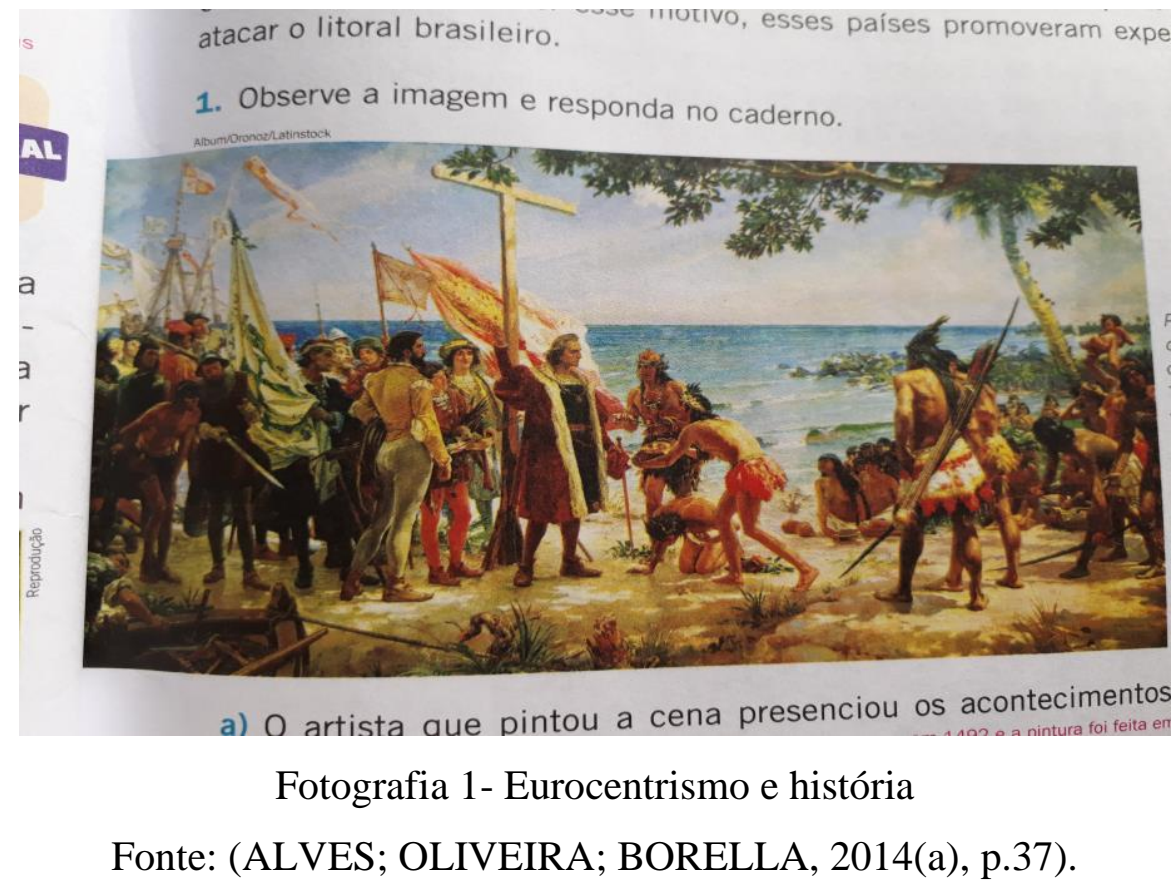

Em suma, ressalta-se o protagonismo dos brancos, assim como a centralidade de seus saberes e técnicas, na narrativa dos fatos e eventos históricos. Reproduzem-se visões (bastante contestadas pelas ciências sociais) e conceitos como o de "descoberta" do "Novo Mundo" ou "começo" da história da América, fenómenos e realidades ontológicas dependentes da chegada dos europeus (Fotografia 2 e Fotografia 3). Essas imagens e discursos exprimem uma perspectiva superficial e acrítica sobre a história indígena: os povos originários parecem não ter história, conflitos, trânsitos e agências no período pré-colonial. A história é contada somente após a chegada do homem "civilizado". Nesse sentido, é fundamental ressaltar que "Si bien la modernidad histórica fue esclavitud para los pueblos indígenas de América fue a la vez una arena de resistencias y conflictos, un escenario para el desarrollo de estrategias envolventes, contrahegemónicas, y de nuevos lenguajes y proyectos indígenas de la modernidad" (THOMSON 2007 apud CUSICANQUI, 2010, p.53; grifo meu). 
RELACult - Revista Latino-Americana de Estudos em Cultura e Sociedade

Revista Latinoamericana de Estudios en Cultura y Sociedad | Latin American Journal of Studies in Culture and Society V. 03, ed. especial, dez., 2017, artigo $n^{\circ} 535$ | relacult.claec.org | e-ISSN: 2525-7870

A chegada dos portugueses ao Novo Mundo

serviço do rei de Portugal, Pedro Alvares Cabral e sua frota estadorias do Oriente e com ordens de to Manuel, em busca das cobiçadas mercante a viagem. Cabral percorria o cami posse das terras que encontrassem durante a vasco da Gama, porém afasto da costa africana, pelo navegando para o Ocidente. No dia 22 de abril de 1500 os portugueses avistaram o território onde hoje em Porto Seguro, atual estado da Bahia, depois de 44 dias de viagem.

Cabral e sua frota tomaram posse do novo território em nome do rei, batizand de llha de Vera Cruz. Os indigenas que aqui já viviam há muito tempo chamavar terra de Pindorama, palavra que na língua tupi significa "terra das palmeiras".

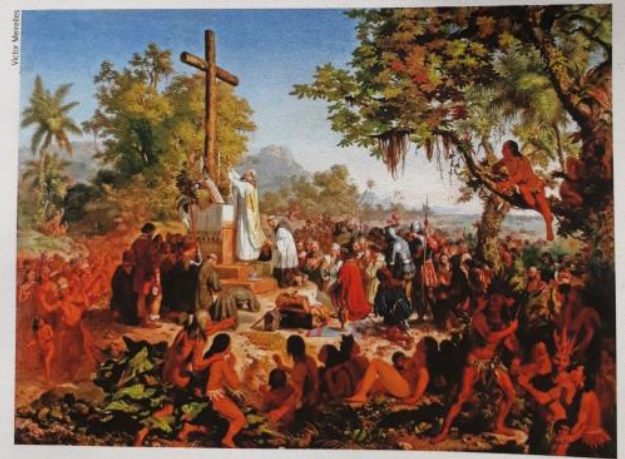

Primeira missa no Bros (10) de Belas Artes, Rio de Je A pintura representa a rezada pelos portugues (ititoral do Brasil em 26 d de 1500 , quando os as assistiram a esse

Faça as atividades no caderno.

1. 0 que aconteceu no dia 22 de abril de 1500 ?

Compare a pintura de Victor Meirelles com a pintura

Fotografia 2- Eurocentrismo e história

Fonte: (ALVES; OLIVEIRA; BORELLA, 2014(a), p.38).

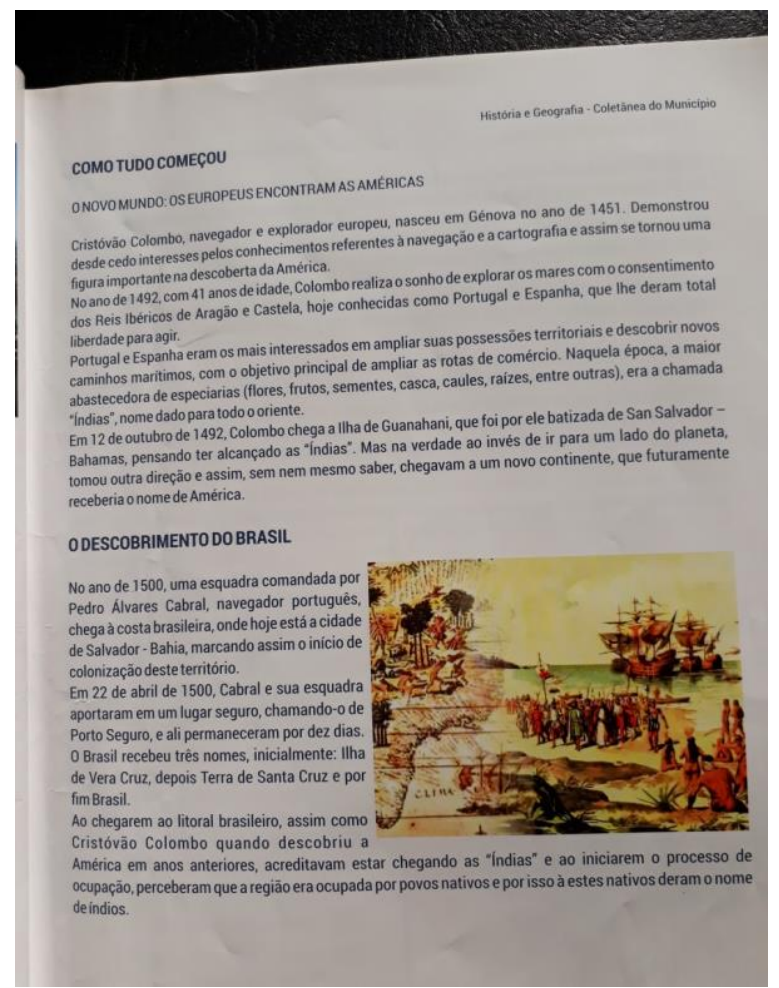

Fotografia 3- Eurocentrismo e história

Fonte: (PREFEITURA DE FOZ DO IGUAÇU, 2016, p.11). 
b) Vazio demográfico e expropriação territorial: Outro elemento corriqueiro em algumas imagens - que, certamente, dialoga com o componente eurocêntrico - é a tese segundo a qual que as terras que "descobriu” o europeu no século XVI eram tidas como áreas desabitadas, isoladas (Fotografia 4) despovoadas, ou ocupadas em tempos remotos pelos índios (Fotografia 5), desconsiderando a ocupação milenar e a territorialidade indígena.

Há de se considerar que essa era uma estratégia bastante rentável para justificar as práticas depredatórias dos brancos sobre o meio ambiente, a qual ainda se invoca como mecanismo discursivo para simplificar os processos de despojo territorial dos índios, invalidando suas lógicas de uso e ocupação do espaço.

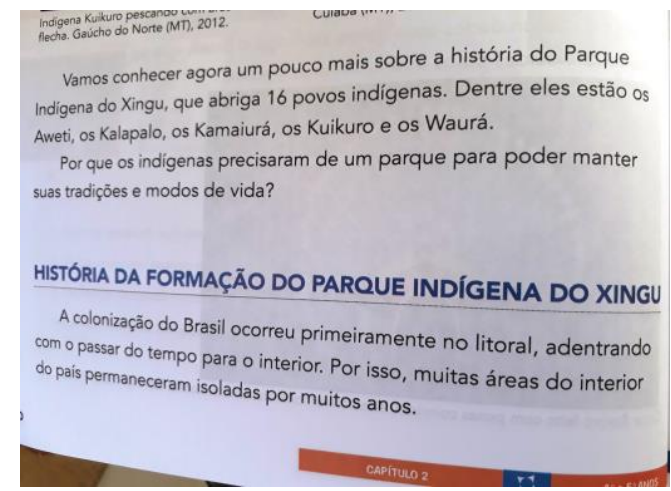

Fotografia 4- Vazio demográfico e expropriação territorial Fonte: (SANTOS; PAIVA; BRAIT, 2014. p.40).

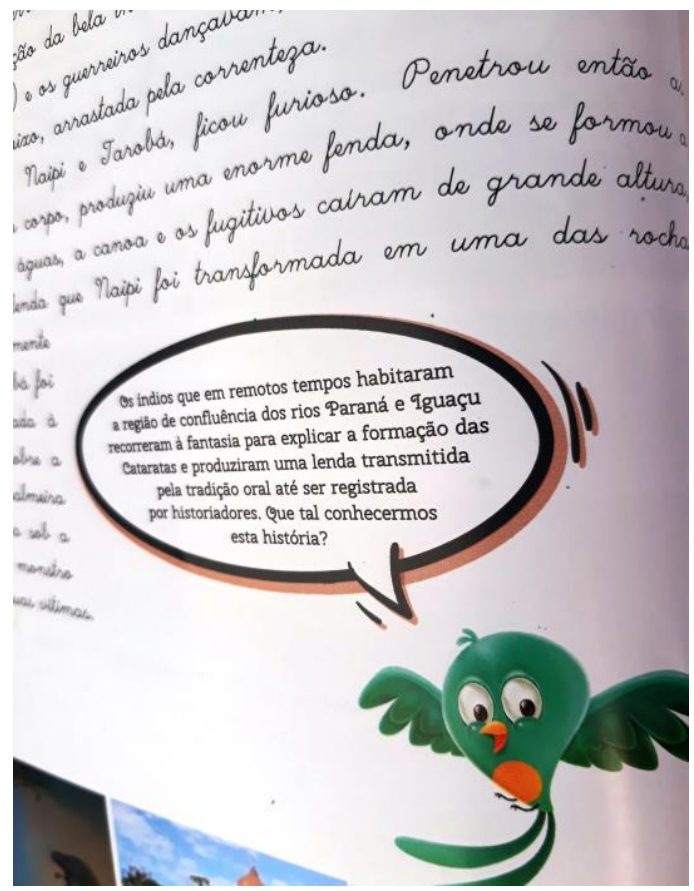

Fotografia 5- Vazio demográfico e expropriação territorial Fonte: (PREFEITURA DE FOZ DO IGUAÇU, 2016, p.30). 
Ao falarmos dos conflitos ocorridos pela disputa dos territórios na nossa região, propiciados, entre outros fatores, pela implantação de projetos desenvolvimentistas como o da Usina Hidrelétrica de Itaipu, observamos que o argumento do tipo "não tinha índio lá", "eles estão invadindo propriedade privada" ou "não há provas de que eles ocuparam esse lugar" é empunhado pelas elites econômico-políticas para atingir seus objetivos.

Nessa engrenagem simbólica, as terras ocupadas pelos povos indígenas são projetadas como improdutivas ou desaproveitadas, justificando a sua intervenção e incorporação nos circuitos comerciais capitalistas. É claro que essas afrontas assumem formas sutis nos livros didáticos. Aparecem sob a forma da omissão, quando se trata o processo de colonização da região de forma vaga, no sentido de não problematizar as relações de desigualdade entre índios ou europeus (Fotografia 6). Ou, por exemplo, na Fotografia 7, afirma-se que os AváGuarani moram na terra indígena Oco’y, de 250 hectares, mas, omite-se o histórico de violência desse processo. Não se comenta que a área original deste grupo indígena - hoje alagada - era de 1500 hectares, e que a terra que ocupam, referida no livro, encontra-se superlotada e sem condições ecológicas de sobrevivência (ALBERNAZ, 2009; PACKER, 2013). Consideramos, então, que o não dito tem uma importância analítica fundamental, pois através dos silêncios e omissões também se emitem mensagens: se invisibilizam acontecimentos cruciais para compreender integralmente a história da região e se atenuam os impactos da máquina colonizadora/industrial para os povos indígenas.

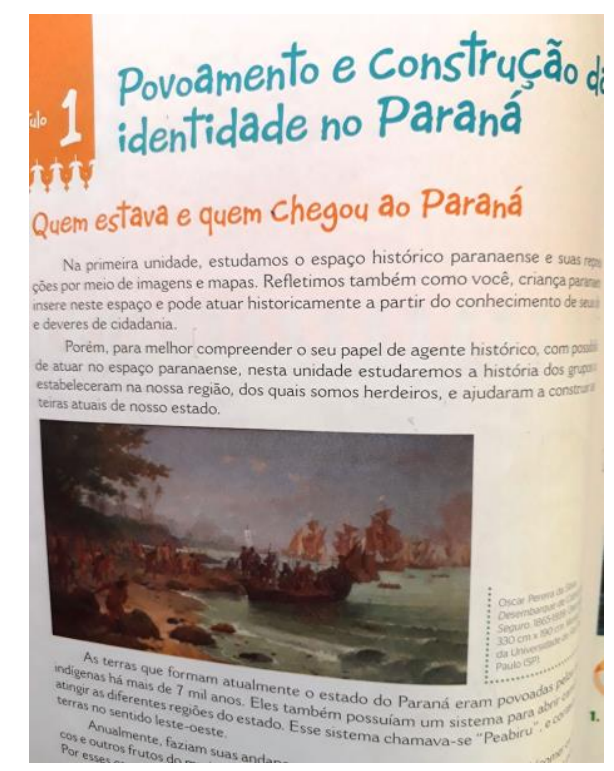

Fotografia 6- Vazio demográfico e expropriação territorial Fonte: (BARROS; MARQUES; PIZZATO, 2011, p.44). 


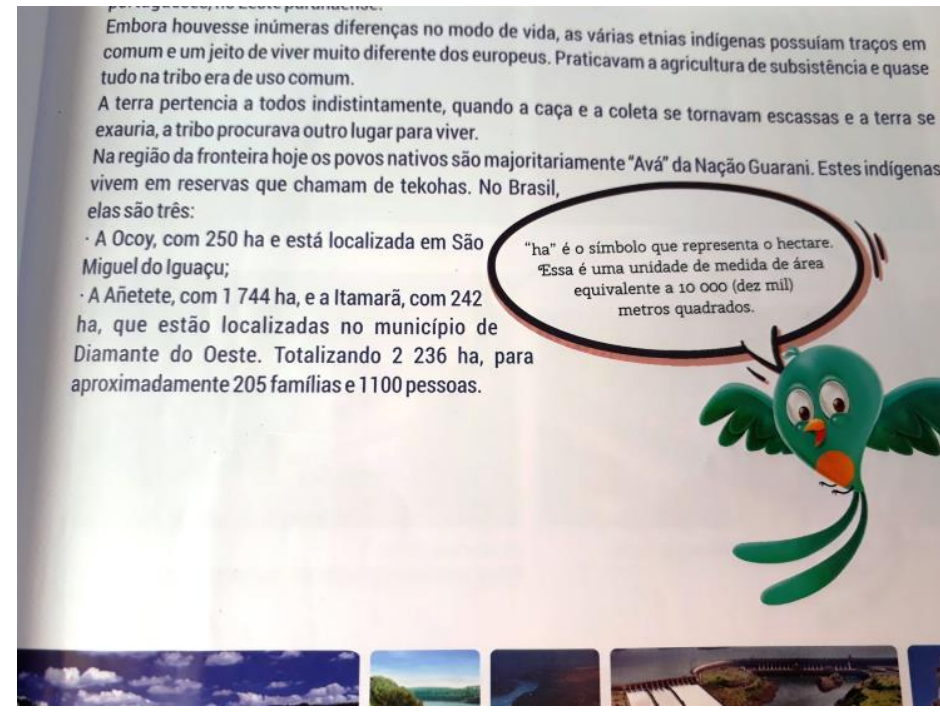

Fotografia 7- Vazio demográfico e expropriação territorial Fonte: (PREFEITURA DE FOZ DO IGUAÇU, 2016, p.13).

c) O fator turístico e discursos desenvolvimentistas: Foz do Iguaçu é uma cidade mundialmente conhecida por sediar as Cataratas do Iguaçu e a Usina Hidrelétrica Itaipu, declaradas "maravilha natural" e "maravilha do mundo moderno" recentemente. Isto faz com que o turismo seja o principal setor econômico do município. Milhares de turistas, além de visitantes nacionais e estrangeiros percorrem a cidade e seus atrativos. Certamente a infraestrutura, o planejamento urbanístico e a organização espacial desse município paranaense estão voltadas para os viajantes. Esse imaginário do município como polo turístico se reflete na produção local dos livros didáticos. Um livro adota uma diretriz que promove e destaca a potencialidade turística de Foz do Iguaçu (Fotografia 8), e, ao mesmo tempo, apela um discurso a favor do desenvolvimentismo. Em outra obra se realçam os benefícios da construção da barragem da Itaipu e da expansão da indústria agrícola no sul do país (Fotografia 9 e Fotografia 10), episódios que, como sabemos, foram - e ainda são completamente contrários aos interesses dos Guarani, e prejudiciais ao meio ambiente, cujos efeitos não são aprofundados em detalhes. Nesse sentido, fica evidente que estas imagens propagam as ideologias capitalistas como formas de desenvolvimento humano, tendo uma implicância na ideia generalizada do índio como empecilho ao progresso do país, uma vez que são tidas como populações "atrasadas" e "primitivas". 

V. 03, ed. especial, dez., 2017, artigo ${ }^{\circ} 535$ | relacult.claec.org | e-ISSN: 2525-7870

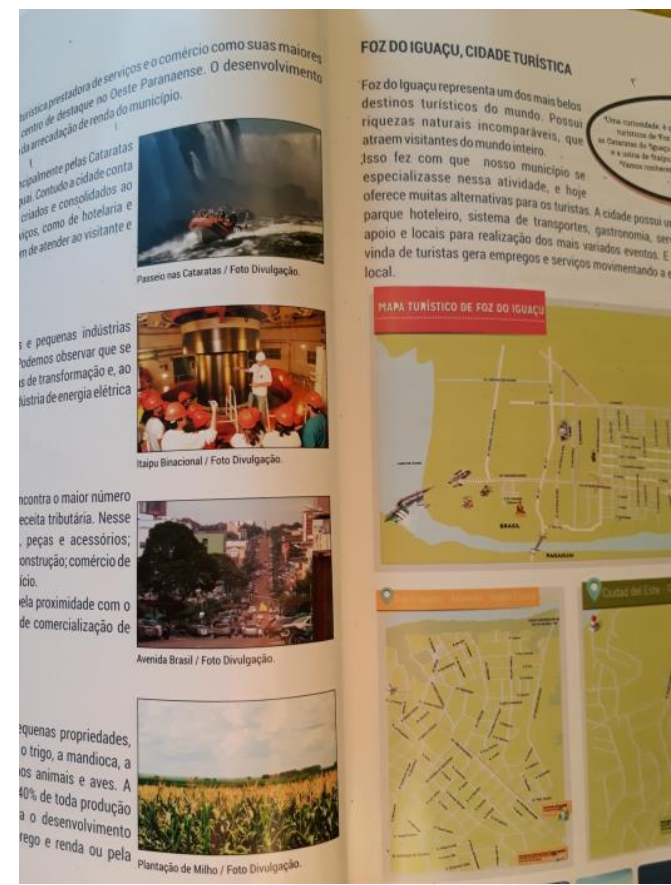

Fotografia 8- Vazio demográfico e expropriação territorial

Fonte: (PREFEITURA DE FOZ DO IGUAÇU, 2016, p.26-27).

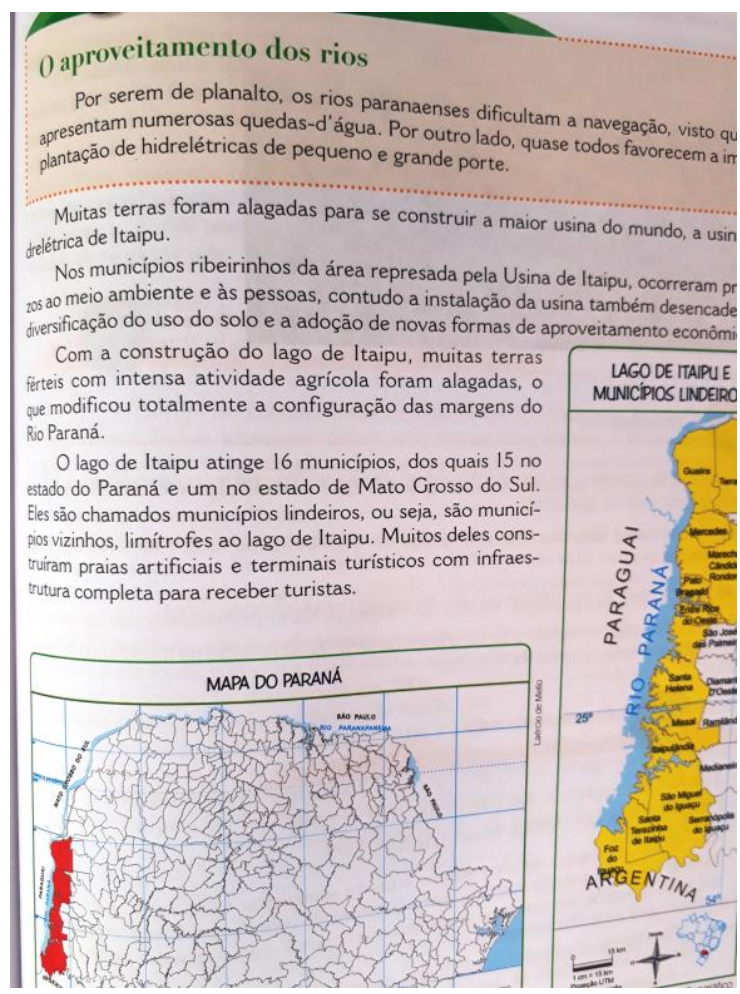

Fotografia 9- O fator turístico e discursos desenvolvimentistas

Fonte: (BARROS; MARQUES; PIZZATO, 2011, p.117). 


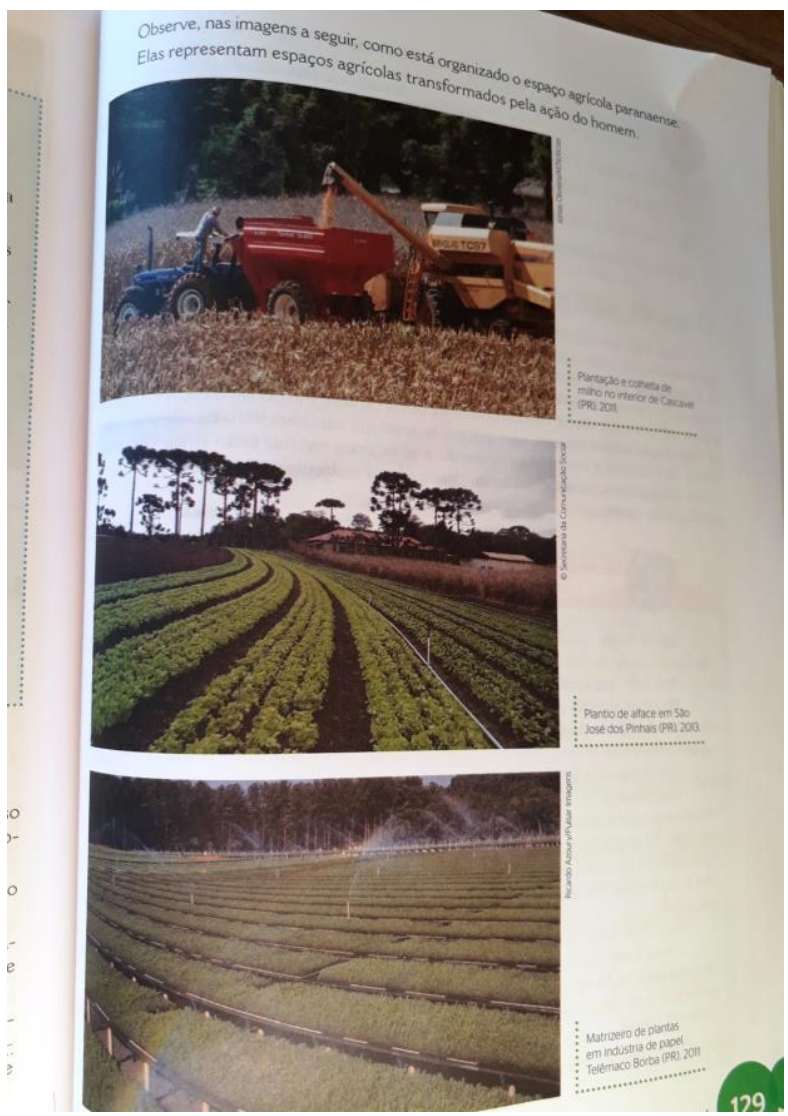

Fotografia 10- O fator turístico e discursos desenvolvimentistas

Fonte: (BARROS; MARQUES; PIZZATO, 2011, p.129).

e) Tradições e resistências: É fato que na maioria das imagens exibidas nos textos escolares continua representando-se um indígena genérico e estereotipado (Fotografia 11). A clássica concepção de índio nu ou seminu, com penas e cocar, e, sobretudo, que mora no mato. Esta é uma concepção da cultura como "congelada", que denota um entendimento dos povos indígenas como pertencentes ao passado remoto e a contextos isolados. Embora se percebe um destaque aos costumes, rituais e características dos índios, são poucos os registros visuais de indígenas em contextos urbanos, assumindo papeis ou profissões nas sociedades metropolitanas. Nesse sentido, um desafio a superar é desconstruir aquela ideia de que o índio somente mora na Amazônia. Em palabras de Cusicanqui (2010, p.7), "lo indio no puede reducirse a lo arcaico ni lo originario convertirse en un estereotipo más. La actualidad de nuestras abigarradas ciudades no puede pensarse sin ese conjunto de desplazamientos territoriales que atraviesan todo tipo de fronteras (de países, oficios, costumbres, lenguajes, comidas, etc.). Es en ese ir y venir incesante donde se constituye la trama material de nuestra vida diaria." 


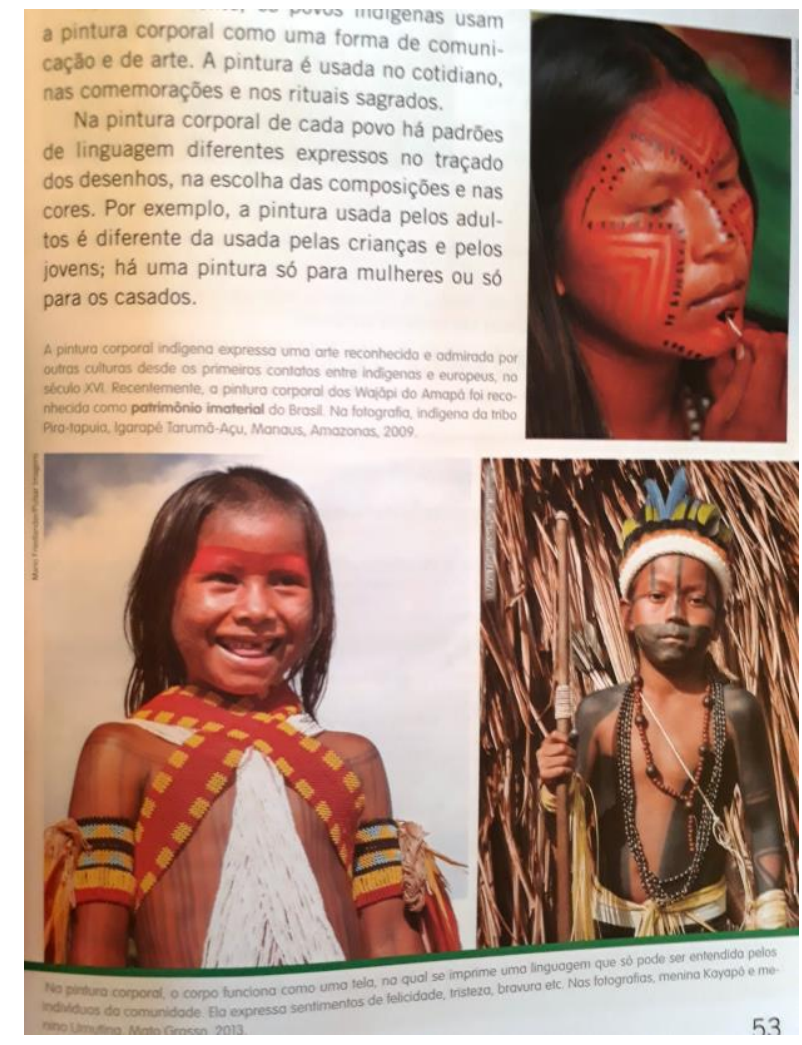

Fotografia 11 - Tradições e resistências

Fonte: (ALVES; OLIVEIRA; BORELLA, 2014(a), p.38).

A carência de conteúdos mais significativa dos livros didáticos é diz respeito à omissão da questão fundiária e os conflitos decorrentes da apropriação ilegal de suas terras, por parte dos consórcios privados e do Estado. Apesar de tudo, tem que ser sublinhado que, em comparação com os livros didáticos produzidos em outrora, os materiais atuais dão um maior destaque aos povos indígenas, e inclusive, se menciona brevemente sua resistência (Fotografia 12 e Fotografia 13). Ainda assim, consideramos como um avanço o fato de incluir a temática indígena na pauta editorial e gráfica, destacando, é claro, que devem haver mudanças significativas na forma como se abordam essas questões.

Em termos gerais, observa-se uma preocupação em explicar o cotidiano e as tradições indígenas, com base em fontes históricas ou antropológicas. Também há uma preocupação em abordar uma história regional, distanciando-se de explicações genéricas sobre os acontecimentos e realidades históricas. De alguma maneira, a diversidade cultural é celebrada, o que demonstra um maior rigor acadêmico na elaboração destes textos. São difundidas informações mais atualizadas, embasadas teoricamente, que tem certo cuidado com o conceito de cultura. Em um dos livros analisados, encontram-se, por exemplo, algumas referências ao povo indígena Guarani bem como a suas formas de resistência. 


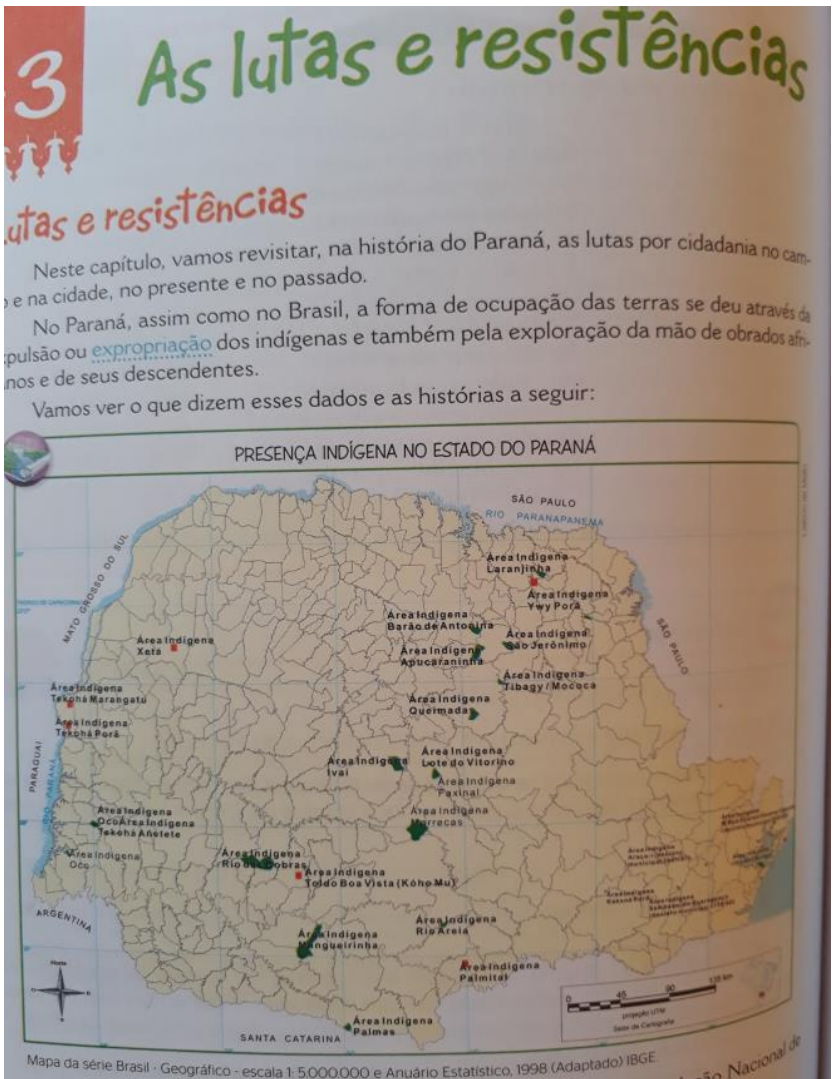

Fotografia 12 - Tradições e resistências

Fonte: (BARROS; MARQUES; PIZZATO, 2011, p.166).

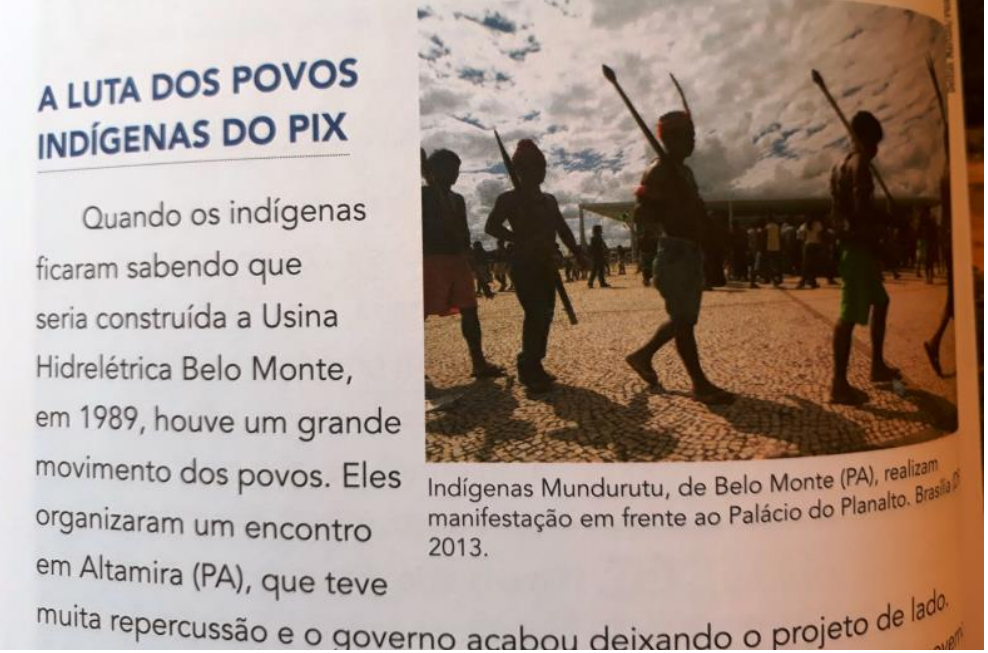

Fotografia 13 - Tradições e resistências

Fonte: (SANTOS; PAIVA; BRAIT, 2014. p.52). 


\section{Considerações finais}

A instituição escolar tem sido um local ocupado e governado historicamente pelos brancos desde tempos coloniais, usado para marcar a diferença e projetar uma visão epistêmica sobre a realidade, a partir da qual recolhem vantagens materiais e simbólicas. Nesse sentido, nesta pesquisa valorizamos o livro didático como um objeto cultural produto de processos históricos e interações sociais (MUNAKATA 2013; CHOPPIN 2004; CHARTIER 1990), assim como portador de certos interesses simbólicos e materiais. Os livros didáticos e manuais escolares constituem uma lente que faz evidente o lugar onde se produz o conhecimento fabricado pela modernidade/colonialidade (CASTRO-GÓMEZ e GROSFOGUEL, 2007, p.88).

Observamos que os autores e autoras dos livros didáticos tem se preocupado em incluir imagens que destaquem aspectos relevantes das sociedades indígenas tais como organização social e política, a produção artística e cultural, os rituais, entre outros. De alguma maneira, estes povos já não são ignorados completamente nos conteúdos. Contudo, ressaltamos que ainda há muito por fazer para representar os grupos étnicos enquanto segmentos sociais diferenciais, ativos e como agentes de seu próprio destino (MONTEIRO, 1999), o que, de alguma maneira, nos demonstra que a colonialidade continua vigente na instituição escolar. Nesse sentido, é fundamental lembrar que "o mundo social é também representação e vontade, e existir socialmente é também ser percebido como distinto" (BOURDIEU, 1989, p.118; grifo nosso).

Acreditamos que considerando o panorama proposto pela Lei 11645 de 2008, os livros didáticos conformam um palco promissor para a renovação da história enquanto saber escolar, a partir da transformação das representações sobre o Outro. Nos municípios e regiões brasileiras com presença indígena (como Foz do Iguaçu), avaliar criticamente as formas e instrumentos pelos quais se ensina a história regional e nacional se torna uma tarefa impostergável, pois permite questionar os estereótipos e o (des)conhecimento em relação aos povos indígenas, que acompanham muitos dos processos de violência física e epistêmica. De tal forma, os pesquisadores devem voltar-se para uma compreensão dos índios enquanto sujeitos, e não apenas vítimas, demonstrando que os povos indígenas dialogaram com as novas conjunturas e desempenharam papel ativo nas relações com os colonizadores (WITTMAN, 2015). 


\section{Referências bibliográficas}

ALBERNAZ, Adriana. Antropologia, histórias e temporalidades entre os Ava-guarani de Oco'y (PR). 404 f. Tese (Doutorado) - Programa de Pós-Graduação em Antropologia Social, Universidade Federal de Santa Catarina, Florianópolis, 2009.

ALVES, A.; OLIVEIRA, L.; BORELLA, R. Ligados.com: História, $5^{\circ}$ ano: ensino fundamental: anos iniciais. São Paulo: Saraiva, 2014. 160 p.

ALVES, A.; OLIVEIRA, L.; BORELLA, R. Ligados.com: História, $4^{\mathrm{o}}$ ano: ensino fundamental: anos iniciais. São Paulo: Saraiva, 2014(a). 144p.

AMAN, R. 2010. El indígena "latinoamericano" en la enseñanza: representación de la comunidad indígena en manuales escolares europeos y latino-americanos. Estudios Pedagógicos, vol. 36, $\mathrm{n}^{\mathrm{o}} \quad 2, \quad$ p. 41-50, 2010. Disponível em: http://www.scielo.cl/pdf/estped/v36n2/art02.pdf. Acesso em: 31 nov. 2016.

ATIENZA, E.; VAN DIJK, T.A. Identidad social e ideología en libros de texto españoles de Ciencias Sociales. Revista de Educación, $\mathrm{n}^{\circ}$ 353, p. 67-106, 2010. Disponível em: http://servidormanes.uned.es/mciud/bibliografia/documentos/articulo\%20revista\%20de\%20ed ucacion.pdf. Acesso em: 07 mar. 2017.

BARROS, D.; MARQUES, M.; PIZZATO, M.; LAGEMANN, T. Paraná povo e chão: história e geografia regional, $4^{\circ}$ ou $5^{\circ}$ ano. Curitiba: Base editorial, 2011. 200p.

BOURDIEU, P. A identidade e representação: elementos para uma reflexão crítica sobre a ideia de região. In: . O poder simbólico, Lisboa, Difel, 1989. p. 107-132.

BRASIL. Lei $n^{o}$ 11.645, de 10 março de 2008. Disponível em: http://www.planalto.gov.br/ccivil_03/_ato2007-2010/2008/lei/111645.htm. Acesso em: 26 julho 2017.

BURKE, Peter. Visto y no visto: El uso de la imagen como documento histórico. Barcelona: Crítica, 2005. 272 p.

BRIGHENTI, C. A colonialidade e decolonialidade no ensino da história e cultura indígena. In: SOUZA, F. de; WITTMANN, L. Protagonismo indígena na História. Tubarão, Erechim: Copiart, UFFS, 2016. p. 231-254.

BRIGHENTI, C. Estrangeiros na própria terra: presença Guarani e Estados Nacionais. Florianópolis: EdUFSC; Chapecó: Argos, 2010. 282 p.

CASTRO-GÓMEZ, S.; GROSFOGUEl, R. (Org.). El giro decolonial: reflexiones para una diversidad epistémica más allá del capitalismo global. Bogotá: Siglo del Hombre Editores: Universidad Central: Instituto de Estudios Sociales Contemporáneos: Pontificia Universidad Javeriana: Instituto Pensar, 2007. 308 p. 
CASTRO-GÓMEZ, S. Ciências sociais, violência epistêmica e o problema da "invenção do outro”. In: LANDER, E. (Org.). A colonialidade do saber: eurocentrismo e ciencias sociais. Perspectivas latinoamericanas. Buenos Aires: Coleccion Sur Sur, CLACSO, 2005. p. 80-87.

CHARTIER, R. O mundo como representação. Estudos Avançados, vol.5, nº.11, p. 172-191, 1991. Disponível em: http://www.scielo.br/pdf/ea/v5n11/v5n11a10.pdf. Acesso em: 14 jan. 2017.

CHARTIER, R. A história cultural entre práticas e representações. Trad. de Maria Manuela Galhardo. Lisboa: Difusão Editora, 1988, 244 p.

CHOPPIN, A. História dos livros e das edições didáticas: sobre o estado da arte. Educação e Pesquisa. São Paulo, vol. 30, nº. 3, sep./dez., p. 549-566, 2004. Disponível em: http://www.scielo.br/pdf/ep/v30n3/a12v30n3.pdf. Acesso em: 15 out. 2016.

CUSICANQUI, Silvia. Ch'ixinakax utxiwa : una reflexión sobre prácticas y discursos. Buenos Aires: Tinta Limón, 2010. 80 p.

DE SOUZA SANTOS, B. Descolonizar el saber, reinventar el poder. Montevideo: Trilce, 2010. $111 \mathrm{p}$.

ESPINOSA, M. Ese indiscreto asunto de la violencia: modernidad, colonialidad y genocidio en Colombia. In: CASTRO-GÓMEZ, S.; GROSFOGUEl, R. (Org.). El giro decolonial: reflexiones para una diversidad epistémica más allá del capitalismo global. Bogotá: Siglo del Hombre Editores: Universidad Central: Instituto de Estudios Sociales Contemporáneos: Pontificia Universidad Javeriana: Instituto Pensar, 2007. p, 267-288.

GOBBI, I. O que os livros didáticos dizem sobre os povos indígenas?. In: TASSSINARI, A.; ALBUQUERQUE, M.; GRANDO, B. (Orgs). Educação indígena: reflexões sobre noções nativas de infância, aprendizagem e escolarização. Florianópolis: Editora da UFSC, 2012, p. 223-242.

GONZALEZ CASANOVA, P. El colonialismo interno. In: De la sociologia del poder a la sociologia de la explotación: pensar América Latina en el siglo XXI. Bogotá: Siglo del Hombre Editores y Clacso, 2009, p.129-156.

GUANAES, S. O Estado Nacional e as políticas desenvolvimentistas: o "cerco articulado" contra os Guarani na Tríplice Fronteira Sul. Tessituras: Revista de Antropologia e Arqueologia, Pelotas, vol. 3, $\mathrm{n}^{\mathrm{o}}$ 1, jan./jun, p. 307-336, 2005. Disponível em: https://periodicos.ufpel.edu.br/ojs2/index.php/tessituras/article/view/5553/4155. Acesso em: 11 set. 2016.

GRUPIONI, L. Imagens contraditórias e fragmentadas: sobre o lugar dos índios nos livros didáticos. Revista Brasileira de Estudos Pedagógicos, Brasília, vol. 77, n ${ }^{\circ}$ 186, p. 422-437, 1996. Disponível em: http://rbep.inep.gov.br/index.php/rbep/article/view/1088/1062. Acesso em: 06 jul. 2016.

KOPENAWA, D.; ALBERT, B. A queda do céu : palavras de um xamã Yanomami. São Paulo: Companhia das Letras, 2016. 729 p. 
MIGNOLO, W. Capitalismo y geopolítica del conocimiento. In: DUBE, S.; DUBE, I.; MIGNOLO, W. (Eds.). Modernidades coloniales. México: Colegio de México, 2004. p. 227255.

MONTEIRO, J. 1999. Armas e armadilhas: história e resistência dos índios. In: NOVAES, A. (Org.). A outra margem do Ocidente. São Paulo: Companhia das Letras, 1999. p. 238-248.

MUNAKATA, K. 2013. O livro didático: alguns temas de pesquisa. Revista Brasileira de História da Educação, Campinas, vol. 12, nº3, set./dez., 2013, p. 179-197, 2013. Disponível em: http://rbep.inep.gov.br/index.php/rbep/article/view/1088/1062. Acesso em: 06 jul. 2016.

OLIVEIRA, T. Olhares que fazem a "diferença": o índio em livros didáticos e outros artefatos culturais. Revista Brasileira de Educação, no 22, jan./abr., 2003. Disponível em: http://www.scielo.br/pdf/rbedu/n22/n22a04. Acesso em: 07 ago. 2016.

PACKER, Ian. Violações dos direitos humanos e territoriais dos Guarani no Oeste do Paraná (1946-1988): subsídios para a Comissão Nacional da Verdade. Centro de Trabalho Indigenista, 2013.

PRATT, M. Os olhos do império: relatos de viagem e transculturação. Bauru: Edusc, 1999. $394 \mathrm{p}$.

PREFEITURA DE FOZ DO IGUAÇU. Coletânea do Município de História e Geografia 2016. Foz do Iguaçu, 2016. 80 p.

QUIJANO, A. Colonialidad del poder y clasificación social. CASTRO-GÓMEZ, S.; GROSFOGUEl, R. (Org.). El giro decolonial: reflexiones para una diversidad epistémica más allá del capitalismo global. Bogotá: Siglo del Hombre Editores: Universidad Central: Instituto de Estudios Sociales Contemporáneos: Pontificia Universidad Javeriana: Instituto Pensar, 2007. p 93-126.

RESTREPO, E.; ROJAS, A. Inflexión decolonial: fuentes, conceptos y cuestionamientos. Popayán, Colombia: Editorial Universidad del Cauca, 2010. 235 p.

SANTOS, K.; PAIVA, L.; BRAIT, R. Culturas e regiões do Brasil $4^{\circ}$ e $5^{\circ}$ anos. São Paulo: Global, 2014. 217 p.

SANTOS, S. C. dos. Índios e brancos no sul do Brasil: A dramática experiência dos Xokleng. Florianópolis: Edeme, 1973. 313 p.

SILVA, E. Ensino e sociodiversidades indígenas: possibilidades, desafios e impasses a partir da Lei 11.645 de 2008. Mneme: Revista de humanidades, vol.15, n 35, jul./dez., p.21-37, 2014. Disponível em: https://periodicos.ufrn.br/mneme/article/view/7485/5816. Acesso em: 07 ago. 2016.

SILVA, A. Implantação da Lei 11.645/2008 no Brasil: um histórico de mobilizações e conquistas. In: SILVA, Edson; SILVA, Maria da Penha da, (orgs.). A temática indígena na sala de aula: reflexões para o ensino a partir da Lei 11.645/2008. Recife: Editora Universitária da UFPE, v. 1, 2013, p. 101-136. 
SILVA, E; SILVA, M. As diversidades étnicas no Brasil: desafios às práticas escolares. In A temática indígena na sala de aula: reflexões para o ensino a partir da Lei 11.645/2008. Recife: Editora Universitária da UFPE, v. 1, 2013, p. 181-209.

SPIVAK, G. Can the Subaltern Speak?. In: NELSON, C; GROSSBERG, L. (Eds.). Marxism and the Interpretation of Culture. Urbana: U of Illinois, 1988. p. 271-313.

TODOROV, T. A Conquista da América A questão do Outro. São Paulo: Martins Fontes, 2010. 387 p.

YAÑES, C. Representaciones sociales de las identidades en los textos escolares de ciencias sociales en Colombia. Cadernos de Educação, no 37, set./dic., p. 15 - 38, 2010. Disponível em: https://periodicos.ufpel.edu.br/ojs2/index.php/caduc/article/view/1578/1464. Acesso em: 07 jul. 2017. 